\title{
Investigation of the morphometric features of bony nasolacrimal canal: a cone-beam computed tomography study
}

\author{
Ö. Okumuş
}

Altınbas University, Faculty of Dentistry, Department of Dentomaxillofacial Radiology, Istanbul, Turkey

[Received: 16 July 2019; Accepted: 23 July 2019]

Background: The aim of this study was to investigate the diameters of the bony nasolacrimal canal by cone-beam computed tomography (CBCT) in normal adult Turkish population and the effect of gender and age on the nasolacrimal canal diameter.

Materials and methods: The randomly selected 100 patients aged from 18 to 83 years were analysed, a total of 200 nasolacrimal canals were examined using $C B C T$. The anteroposterior and transverse diameters, the sectional area of the bony nasolacrimal canal and the angle between the bony canal and the nasal floor were measured in axial, sagittal CBCT scan.

Results: The anteroposterior diameter of the bony nasolacrimal canal was $6.56 \pm$ $\pm 1.53 \mathrm{~mm}$, and the transverse diameter was $4.34 \pm 1.03 \mathrm{~mm}$. The sectional area of the bony nasolacrimal canal was $7.39 \pm 3.29 \mathrm{~mm}^{2}$, and the angle between the bony canal and the nasal floor was $73.46 \pm 6.77^{\circ}$. No significant difference in the anteroposterior diameter, the transverse diameter and the sectional area of the bony nasolacrimal canal between ages. The angle between the bony canal and the nasal floor was significantly greater in female.

Conclusions: This study may provide useful information of morphometric features of the bony nasolacrimal canal. The detailed anatomical knowledge of bony nasolacrimal canal morphology may help the clinicians plan the treatment options. (Folia Morphol 2020; 79, 3: 588-593)

Key words: cone beam computed tomography, diameter, morphology, nasolacrimal canal

\section{INTRODUCTION}

The nasolacrimal canal is bordered medially by palatine bone and the inferior turbinate in the nose and laterally by maxillary bone and it opens at the inferior meatus of the nose. The nasolacrimal canal is 12 to $18 \mathrm{~mm}$ long and tear fluid is drained by the nasolacrimal duct [17]. Embryological, the nasolacrimal canal starts forming around 5 weeks of gestation. It starts out as a linear thickening of ectoderm located in a groove between the nasal and maxillary prominences. This thickening eventually separates into a solid cord and sinks into the surrounding mesenchyme. Over time the cord canalizes forming the lacrimal sac and the beginning of the nasolacrimal canal. The nasolacrimal duct extends intranasally until it exits under the inferior turbinate [10].

The nasolacrimal canal obstruction leading to epiphora is a common ophthalmologic problem [13]. The 
nasolacrimal canal obstruction can be congenital or acquired. The acquired lacrimal duct obstruction was classified into primary and secondary by Bartley [2]. The aetiology of secondary obstruction includes neoplasm, sarcoidosis, facial trauma, surgery, or Wegener granulomatosis [11]. Primary acquired nasolacrimal duct obstruction (PANDO) is known idiopathic, and occurs more frequently in female patients [11]. Although the exact aetiology of PANDO remains unknown, some anatomical factors had been defined [8]. A substantial aetiology is a smaller diameter of the nasolacrimal canal, and studies have reported gender and racial variations in dry skull studies [8]. The differences in the diameter of the bony nasolacrimal canal have been thought to relate with gender and age [18].

Computed tomography (CT) is one of the most available imaging method providing high-resolution images and reliable information to assess the nasolacrimal duct diameter [5]. Cone-beam computed tomography (CBCT) which is widely used in dentistry in the recent years, is preferred to CT due to low cost, high resolution, a lower dose of radiation and better image quality. CBCT allows diagnosis by providing three-dimensional data about the anatomical formations. The data acquired by CBCT presents coronal, sagittal and axial sections, decreasing the superposition of anatomical formations. These advantages help the clinician to understand the whole anatomical formation of the tissue [16].

Therefore, the aim of this study was to evaluate the diameters of the bony nasolacrimal canal by CBCT in a normal adult Turkish population and to evaluate how these diameters are affected by gender and age.

\section{MATERIALS AND METHODS}

In this retrospective study in which were randomly selected 100 patients aged from 18-83 years were analysed, a total of 200 nasolacrimal canals were examined using CBCT. The study was carried out in the Department of Dentomaxillofacial Radiology of Altınbas University of Faculty of Dentistry. The informed consent form was routinely received from all patients before radiographic examinations. Patients with clinical or radiologic evidence of orbital or paranasal sinus pathology or prior nasolacrimal and sinus surgery were excluded and the images only included in the axial view of the nasolacrimal canal level of the scanning protocol were used.

All CBCT examinations were acquired with NewTom Vgi evo (CeflaGroup, Verona, Italy). During the expo- sure, the patients were standing and the patient head was positioned to be the sagittal and vertical planes are perpendicular to the floor and the orbitomeatal plane was parallel to the floor and kept stable with special headband and chin support to prevent patient movement, and the device has made a single rotation of $360^{\circ}$ around the patient's head in each beam.

All measurements were made by the specialist of dentomaxillofacial radiology (O.O.). The anteroposterior and transverse diameters and the sectional area of the bony nasolacrimal canal at the level of the infraorbital margin were measured in the axial CBCT scan image on NNT Viewer (CeflaGroup, Verona, Italy) software programme. The first that showed the central portion of the inferior orbital rim was chosen (Fig. 1). The area of the nasolacrimal duct at the measured point was determined using the equation for area of an ellipse.

Also on the sagittal CBCT scan, a line connecting the most proximal portion of the bony nasolacrimal canal to the distal end of the bony nasolacrimal canal was drawn and the angle between this line and the line parallel to the nasal floor was measured (Fig. 2).

The findings were analysed statistically and the effect of gender and age on the nasolacrimal canal diameter were investigated.

\section{Statistical analysis}

For the statistical analyses, the IBM SPSS Statistics 22 (IBM SPSS, Turkey) programme was used while assessing the findings of the study. The normal distribution of the parameters was evaluated by Shapiro-Wilks test. The one-way ANOVA test was used for comparison of the parameters of normal distribution in comparison of quantitative data as well as descriptive statistical methods (mean, standard deviation [SD], and frequency). The Tukey HDS test was used to determine the difference between groups of normal distribution. Student's t-test was used to compare normal distribution parameters between two groups. Values of $<0.05$ were considered as significant statistically $(p<0.05)$.

\section{RESULTS}

There were 100 patients ( $58 \%$ female, $42 \%$ male) and age ranged from 18 to 83 years with a mean of $41.62 \pm 16.02$ years. There was no significant difference between males and females in all age groups.

The anteroposterior diameter of the bony nasolacrimal canal was $6.56 \pm 1.53 \mathrm{~mm}$ (mean $\pm \mathrm{SD})$, and 


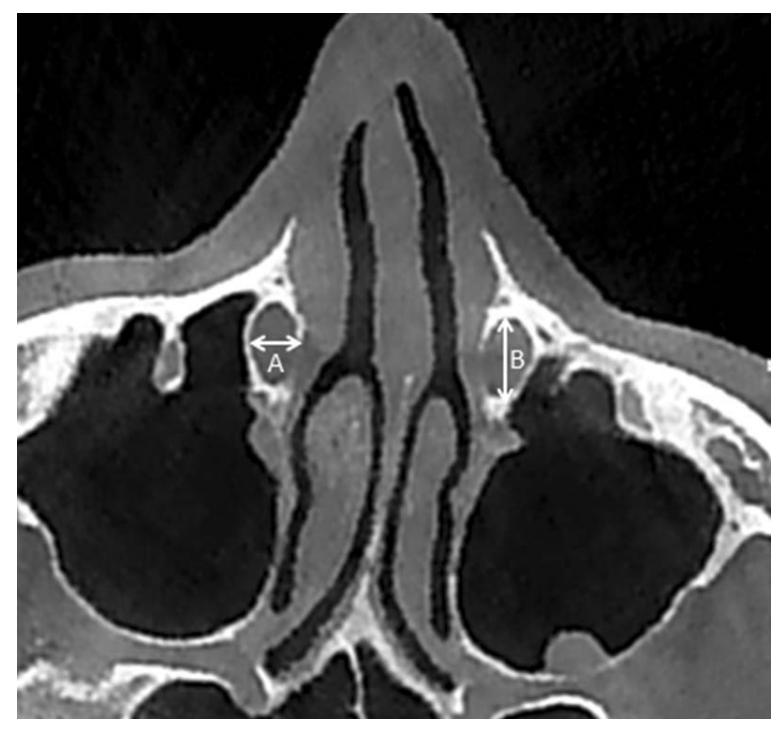

Figure 1. The anteroposterior (arrow $B$ ) and the transverse diameter (arrow A) at the level of the infraorbital margin in the axial cone-beam computed tomography scan.

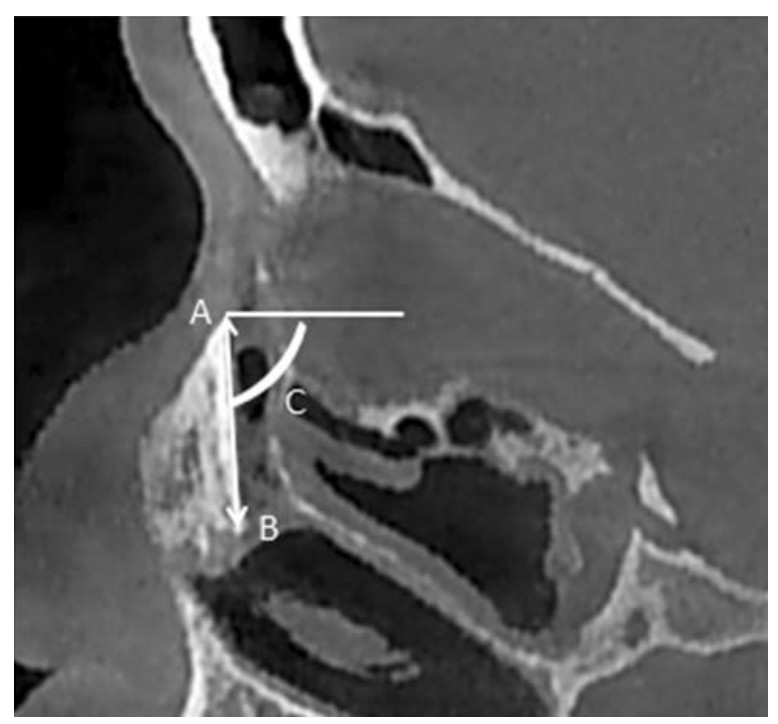

Figure 2. Line connecting the most proximal part of the bony nasolacrimal canal (point A) to the distal end of the bony nasolacrimal canal (point $B$ ), the angle between this line and the line parallel to the nasal floor (point $\mathrm{C}$ ) in the sagittal cone-beam computed tomography scan.

the transverse diameter was $4.34 \pm 1.03 \mathrm{~mm}$. The sectional area of the bony nasolacrimal canal was $7.39 \pm 3.29 \mathrm{~mm}^{2}$, and the angle between the bony canal and the nasal floor was $73.46 \pm 6.77^{\circ}$ (Table 1 ).

The angle between the bony canal and the nasal floor was significantly greater in female patients $(74.66 \pm 6.62)$ than in male patients $(71.8 \pm 6.66$; $p<0.003)$. No statistically significant difference
Table 1. The mean anatomical diameters of bony nasolacrimal canal

\begin{tabular}{lccccc}
\hline Side & $\mathbf{n}$ & $\begin{array}{c}\text { AP } \\
\text { diameter } \\
{[\mathrm{mm}]}\end{array}$ & $\begin{array}{c}\text { Transverse } \\
\text { diameter } \\
{[\mathrm{mm}]}\end{array}$ & $\begin{array}{c}\text { Sectional } \\
\text { area } \\
{\left[\mathbf{m}^{2}\right]}\end{array}$ & $\begin{array}{c}\text { Angle } \\
\text { [degree] }\end{array}$ \\
\cline { 2 - 6 } & & Mean \pm SD & Mean \pm SD & Mean \pm SD & Mean \pm SD \\
\hline Right & 100 & $6.51 \pm 1.61$ & $4.25 \pm 1.04$ & $7.22 \pm 3.46$ & $72.81 \pm 7.29$ \\
Left & 100 & $6.61 \pm 1.44$ & $4.43 \pm 1.02$ & $7.55 \pm 3.11$ & $74.11 \pm 6.16$ \\
Total & 200 & $6.56 \pm 1.53$ & $4.34 \pm 1.03$ & $7.39 \pm 3.29$ & $73.46 \pm 6.77$ \\
\hline
\end{tabular}

AP — anteroposterior; SD — standard deviation

Table 2. The mean anatomical diameters of bony nasolacrimal canal by gender

\begin{tabular}{lccc}
\hline & Female & Male & P \\
\cline { 2 - 3 } & Mean \pm SD & Mean \pm SD & \\
\hline Anteroposterior diameter $[\mathrm{mm}]$ & $6.39 \pm 1,54$ & $6.79 \pm 1.49$ & 0.071 \\
Transverse diameter [mm] & $4.3 \pm 1,03$ & $4.41 \pm 1.04$ & 0.456 \\
Sectional area [m²] & $7.13 \pm 3,25$ & $7.74 \pm 3.33$ & 0.201 \\
Angle [degree] & $74.66 \pm 6.62$ & $71.8 \pm 6.66$ & $0.003^{*}$ \\
\hline
\end{tabular}

Student $t$ test; ${ }^{*} p<0.05 ; S D$ - standard deviation

Table 3. Correlation between age and parameters

\begin{tabular}{lcc}
\hline & \multicolumn{2}{c}{ Age } \\
\cline { 2 - 3 } & R & P \\
\hline Anteroposterior diameter $[\mathrm{mm}]$ & -0.131 & 0.064 \\
Transverse diameter $[\mathrm{mm}]$ & -0.181 & $0.010^{*}$ \\
Sectional area $\left[\mathrm{m}^{2}\right]$ & -0.172 & $0.015^{*}$ \\
Angle [degree] & -0.303 & $0.000^{*}$ \\
\hline
\end{tabular}

Pearson correlation analysis; ${ }^{*} \mathrm{p}<0.05$

was found in the other parameters between genders (Table 2).

All parameters except the anteroposterior diameter were significantly affected by age in the correlation test ( $p<0.05$; Table 3 ). When the subjects were divided into five age groups, no statistically significant difference was found in the anteroposterior diameter, the transverse diameter and the sectional area of the bony nasolacrimal canal. However, the angle between the bony canal and the nasal floor was affected significantly in age groups (Table 4).

The angle between the bony canal and the nasal floor was significantly higher in female subjects under the age of 30 ( $p<0.05$ ). No statistically significant difference was found in other parameters between genders. The age significantly affected the anteropos- 
Table 4. Mean values of bony nasolacrimal canal by the age groups

\begin{tabular}{lcccccc}
\hline & \multicolumn{3}{c}{ Age [years] } & P & \\
\cline { 2 - 6 } & $\mathbf{3 0}$ & $\mathbf{3 0 - 3 9}$ & $\mathbf{4 0 - 4 9}$ & $\mathbf{5 0 - 5 9}$ & $\geq \mathbf{6 0}$ \\
\cline { 2 - 6 } & Mean \pm SD & Mean \pm SD & Mean \pm SD & Mean \pm SD & Mean \pm SD & \\
\hline Anteroposterior $[\mathrm{mm}]$ & $6.87 \pm 1.84$ & $6.48 \pm 1.3$ & $6.41 \pm 1.38$ & $6.47 \pm 1.55$ & $6.32 \pm 1.21$ & 0.454 \\
Transverse $[\mathrm{mm}]$ & $4.54 \pm 1.01$ & $4.33 \pm 1$ & $4.61 \pm 1.18$ & $4.03 \pm 1.1$ & $4.18 \pm 0.8$ & 0.082 \\
Sectional area $\left[\mathrm{m}^{2}\right]$ & $8.14 \pm 3.84$ & $7.24 \pm 2.83$ & $7.6 \pm 3.07$ & $6.82 \pm 3.6$ & $6.72 \pm 2.2$ & 0.212 \\
Angle [degree] & $76.13 \pm 7.39$ & $74.76 \pm 4.96$ & $71.36 \pm 8.15$ & $70.76 \pm 5.32$ & $71.61 \pm 6.2$ & $0.000^{*}$ \\
\hline
\end{tabular}

One-way ANOVA test; * $\mathrm{p}<0.05 ; \mathrm{SD}-$ standard deviation
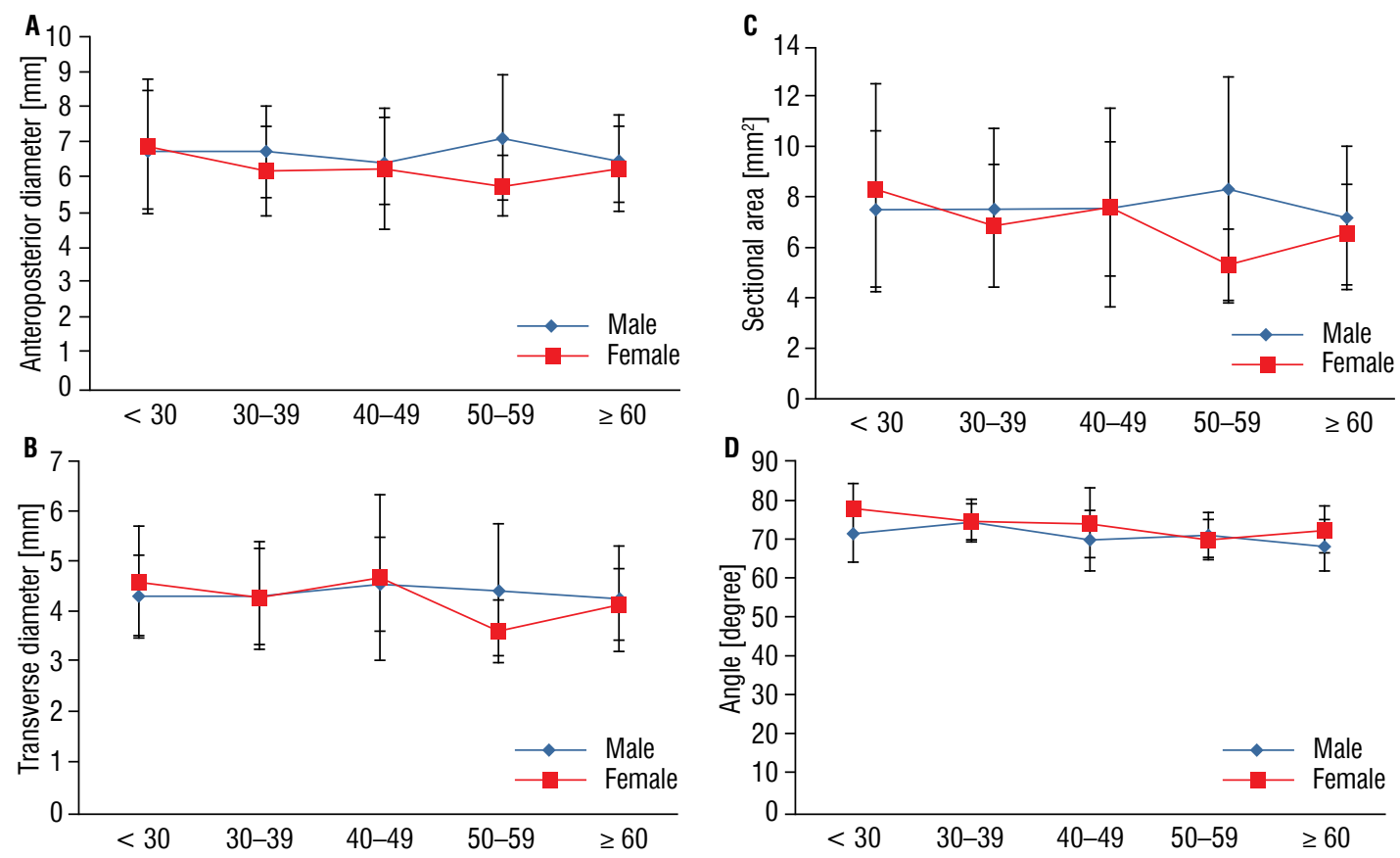

Figure 3. The age distribution of the bony nasolacrimal canal measurements. The anteroposterior diameter (A), transverse diameter (B), sectional area canal (C), and angle (D).

terior diameter $(p=0.004)$, the transverse diameter $(p=0.017)$ and the sectional area of the bony nasolacrimal canal $(p=0.007)$ in female patients between the ages of 50-59. All parameters were not significantly affected in subjects between $30-39$ years, $40-49$ years and over age of the 60 (Fig. 3).

\section{DISCUSSION}

Although the certain aetiology of PANDO is still unclear, many situations such as smoking, maxillofacial trauma and history of dacryocystitis have described [23]. Also one of the defined etiologic factors is relatively smaller diameter of the nasolacrimal canal. Small changes in the bony nasolacrimal canal diameter may lead to the obstruction by influencing tear flow [11, 12].
The normal diameter of the bony nasolacrimal canal has evaluated by several studies. Janssen et al. [11] evaluated the normal bony nasolacrimal canal diameter in 100 subjects without pathology of nasolacrimal duct and the mean transverse diameter was $3.5 \mathrm{~mm}$ in axial CT images. The transverse diameter was approximately 4.6 and $4.8 \mathrm{~mm}$ in the studies of Duke-Elder and Steinkogler, respectively [6, 19]. The anteroposterior diameter was approximately 6.8 and 4 to $8 \mathrm{~mm}$ in the studies of Steinkogler and Cowen-Hurwitz, respectively [4, 19]. The transverse and anteroposterior diameter were 4.5 and $6.5 \mathrm{~mm}$, respectively in the study of Lee et al. [12] and 5.6 and $5.0 \mathrm{~mm}$ in the study of Shigeta et al. [18]. In our study the anteroposterior diameter of the bony nasolacrimal canal was $6.56 \mathrm{~mm}$, and the transverse diameter 
was $4.34 \mathrm{~mm}$. These differences could be explained by different measurement methods, different patient ages and possibly racial differences.

In some recent studies, gender differences in nasolacrimal canal dimension were reported so it has suggested that PANDO is more frequently in female patients, could be explained by this anatomical difference $[11,18]$. The mean nasolacrimal canal diameter in subjects with normal was $12.3 \pm 2.5 \mathrm{~mm}$ in male and $10.8 \pm 2.5 \mathrm{~mm}$ in female in the study of Ramey et al. [15]. Bulbul et al. [3] compared the anatomical differences of bony nasolacrimal canal diameter between PANDO and non-PANDO patients and detected no significant gender differences in measured measurements. In our study, the mean of anteroposterior diameter was $6.39 \pm 1.54 \mathrm{~mm}$ in female and $6.79 \pm 1.49 \mathrm{~mm}$ in male, the mean of transverse diameter was $4.3 \pm 1.03 \mathrm{~mm}$ in female and $4.41 \pm 1.04 \mathrm{~mm}$ in male, and there was no significant gender difference.

Takahashi et al. [20] reported shorter transverse diameter in female than in male and, on the contrary, no significant gender difference in anteroposterior diameter. Shigeta et al. [18] reported smaller sectional area, anteroposterior and transverse diameter of bony nasolacrimal canal in female patients than in male patients. Furthermore, they reported the smaller bony canal diameter as a cause of greater prevalence of obstruction in female. Lee et al. [12] evaluated the diameters, angles, and sectional area of bony nasolacrimal canal in patients without PANDO and they reported no significant gender differences in diameter, which is similar to our results. Also the angle between the bony canal and the nasal floor was significantly greater in female patients $(74.66 \pm 6.62)$ than in male patients $(71.8 \pm 6.66)$ in our study.

McCormick and Sloan [14] investigated the gender and racial differences in nasolacrimal canal diameter so they concluded that the narrower canals were observed in females and no racial differences.

The effect of age on results of anatomical studies was associated the nasolacrimal canal morphology $[12,15,18]$. Groessl et al. [9] reported an association between the diameter of the nasolacrimal canal and age. Lee et al. [12] investigated the diameters, angles, and sectional area of bony nasolacrimal canal in patients without pathology of nasolacrimal duct and found that these parameters in patients under 10 years old were significantly smaller than in patients over the age of 10. In another study Ela et al. [7] inves- tigated the bony nasolacrimal canal morphology and dimension in children retrospectively. They concluded the positive correlation between the anteroposterior diameter, transverse diameter, sectional area and age. However, they reported that no significant association between gender and parametres. In our study, no statistically significant difference was found in the anteroposterior diameter, the transverse diameter and the sectional area of the bony nasolacrimal canal in age groups.

Janssen et al. [11] and Shigeta et al. [18] reported that the mean angle between the bony canal and the nasal floor was $22.5^{\circ}$ and $78.3^{\circ}$, respectively. In our study, the mean angle between the bony canal and the nasal floor was $73.46^{\circ}$. These differences could be explained by different methods and patient ages and possibly racial differences.

In the literature, there are a few studies using CBCT to investigate the nasolacrimal canal diameter and system [1, 21, 22]. Altun et al. [1] evaluated retrospectively the morphometric changes in the nasolacrimal canal using $C B C T$ in patients with unilateral cleft lip/palate. They concluded that the nasolacrimal canal diameter at the affected side of unilateral cleft lip/palate was narrower than the unaffected side. Wilhelm et al. [22] and Tschopp et al. [21] evaluated the usefulness and safety of $C B C T$ dacryocystography in detecting lesions and determining treatment methods in patients with epiphora so concluded that CBCT dacryocystography is a reliable and time efficient method to assess the nasolacrimal canal system in patients with epiphora.

\section{CONCLUSIONS}

In conclusion, this study may provide useful information of morphometric features of the bony nasolacrimal canal. The detailed anatomical knowledge of bone nasolacrimal canal morphology may help the clinicians plan the treatment options.

\section{REFERENCES}

1. Altun O, Dedeoğlu N, Avci M. Examination of nasolacrimal duct morphometry using cone beam computed tomography in patients with unilateral cleft lip/palate. J Craniofac Surg. 2017; 28(8): e725-e728, doi: $10.1097 /$ SCS.0000000000003848, indexed in Pubmed: 28891896.

2. Bartley GB. Acquired lacrimal drainage obstruction: an etiologic classification system, case reports, and a review of the literature. Part 3. Ophthalmic Plast Reconstr Surg. 1993; 9(1): 11-26, indexed in Pubmed: 8443110.

3. Bulbul E, Yazici A, Yanik B, et al. Morphometric evaluation of bony nasolacrimal canal in a caucasian population with 
primary acquired nasolacrimal duct obstruction: a multidetector computed tomography study. Korean J Radiol. 2016; 17(2): 271-276, doi: 10.3348/kjr.2016.17.2.271, indexed in Pubmed: 26957913.

4. Cowen D, Hurwitz JJ. Anatomy of the lacrimal drainage system. In: Hurwitz JJ, ed. The Lacrimal System, Philadelphia 1996: 15-21.

5. Czyz CN, Bacon TS, Stacey AW, et al. Nasolacrimal system aeration on computed tomographic imaging: sex and age variation. Ophthalmic Plast Reconstr Surg. 2016; 32(1): 11-16, doi: 10.1097/IOP.0000000000000392, indexed in Pubmed: 25675167.

6. Duke-Elder S. Textbook of ophthalmology. Vol I. The development, form and function of the visual apparatus. Kimpton, London 1946.

7. Ela AS, Cigdem KE, Karagoz Y, et al. Morphometric measurements of bony nasolacrimal canal in children. J Craniofac Surg. 2018; 29(3): e282-e287, doi: 10.1097/ SCS.0000000000004316, indexed in Pubmed: 29381609.

8. Fasina O, Ogbole GI. CT assessment of the nasolacrimal canal in a black African Population. Ophthalmic Plast Reconstr Surg. 2013; 29(3): 231-233, doi: 10.1097/ IOP.0b013e3182873d2e, indexed in Pubmed: 23511996.

9. GroessI SA, Sires BS, Lemke BN. An anatomical basis for primary acquired nasolacrimal duct obstruction. Arch Ophthalmol. 1997; 115(1): 71-74, doi: 10.1001/ archopht.1997.01100150073012, indexed in Pubmed: 9006428.

10. Imre A, Imre SS, Pinar E, et al. Transection of nasolacrimal duct in endoscopic medial maxillectomy: implication on epiphora. J Craniofac Surg. 2015; 26(7): e616-e619, doi: $10.1097 /$ SCS.0000000000002115, indexed in Pubmed: 26468843.

11. Janssen AG, Mansour K, Bos JJ, et al. Diameter of the bony lacrimal canal: normal values and values related to nasolacrimal duct obstruction: assessment with CT. AJNR Am J Neuroradiol. 2001; 22(5): 845-850, indexed in Pubmed: 11337326.

12. Lee $H$, Ha S, Lee $Y$, et al. Anatomical and morphometric study of the bony nasolacrimal canal using computed tomography. Ophthalmologica. 2012; 227(3): 153-159, doi: 10.1159/000331986, indexed in Pubmed: 22025179.

13. Linberg JV, McCormick SA. Primary acquired nasolacrimal duct obstruction. A clinicopathologic report and biopsy technique. Ophthalmology. 1986; 93(8): 1055-1063, doi: 10.1016/s0161-6420(86)33620-0, indexed in Pubmed: 3763155
14. McCormick A, Sloan B. The diameter of the nasolacrimal canal measured by computed tomography: gender and racial differences. Clin Exp Ophthalmol. 2009; 37(4): 357-361, doi: 10.1111/j.1442-9071.2009.02042.x, indexed in Pubmed: 19594561.

15. Ramey NA, Hoang JK, Richard MJ. Multidetector CT of nasolacrimal canal morphology: normal variation by age, gender, and race. Ophthalmic Plast Reconstr Surg. 2013; 29(6): 475-480, doi: 10.1097/IOP.0b013e3182a230b0, indexed in Pubmed: 24145910.

16. Scarfe WC, Farman AG, Sukovic P. Clinical applications of cone-beam computed tomography in dental practice. J Can Dent Assoc. 2006; 72(1): 75-80, indexed in Pubmed: 16480609 .

17. Sharma HR, Sharma AK, Sharma R. Modified external dacryocystorhinostomy in primary acquired nasolacrimal duct obstruction. J Clin Diagn Res. 2015; 9(10): NC01-NC05, doi: 10.7860/JCDR/2015/15940.6624, indexed in Pubmed: 26557549.

18. Shigeta Kl, Takegoshi H, Kikuchi S. Sex and age differences in the bony nasolacrimal canal: an anatomical study. Arch Ophthalmol. 2007; 125(12): 1677-1681, doi: 10.1001/ archopht.125.12.1677, indexed in Pubmed: 18071122.

19. Steinkogler FJ. The postsaccal, idiopathic dacryostenosis - experimental and clinical aspects. Doc Ophthalmol. 1986; 63(3): 265-286, doi: 10.1007/BF00160761, indexed in Pubmed: 3780377.

20. Takahashi $Y$, Nakata K, Miyazaki H, et al. Comparison of bony nasolacrimal canal narrowing with or without primary acquired nasolacrimal duct obstruction in a Japanese population. Ophthalmic Plast Reconstr Surg. 2014; 30(5): 434-438, doi: 10.1097//OP.0000000000000238, indexed in Pubmed: 25098445.

21. Tschopp M, Bornstein MM, Sendi P, et al. Dacryocystography using cone beam $C T$ in patients with lacrimal drainage system obstruction. Ophthalmic Plast Reconstr Surg. 2014; 30(6): 486-491, doi: 10.1097/IOP.0000000000000154, indexed in Pubmed: 24833449.

22. Wilhelm KE, Rudorf $H$, Greschus $S$, et al. Cone-beam computed tomography (CBCT) dacryocystography for imaging of the nasolacrimal duct system. Clin Neuroradiol. 2009; 19(4): 283-291, doi: 10.1007/s00062-009-9025-9, indexed in Pubmed: 19936571.

23. Yazici B, Hammad AM, Meyer DR. Lacrimal sac dacryoliths: predictive factors and clinical characteristics. Ophthalmology. 2001; 108(7): 1308-1312, doi: 10.1016/s01616420(01)00596-6, indexed in Pubmed: 11425692. 